\title{
Do discurso empresarial ao discurso da marca - um olhar
}

From entrepreneurial discourse to brand discourse - an overview

Del discurso empresarial al discurso de marca - una mirada

- Professora Coordenadora aposentada do Politécnico de Leiria.

- Investigadora do Centro de Estudos de Linguística Geral e Aplicada (Celga-Iltec) da Universidade de Coimbra.

- E-mail: carminda.silvestre@gmail.com 


\section{Resumo}

As pessoas estão envolvidas em processos de trabalho, em estruturas económicas e sociais nas quais a operacionalização de um determinado discurso se vai reconfigurando em novas práticas e respetivas estruturas organizacionais. A linguagem na sua relação dialética com a sociedade faz parte desse processo de mudanças. 0 presente depoimento visa mapear mudanças discursivas em progresso através de um olhar pessoal, testemunhando como a área da linguística aplicada às empresas emerge e se adapta e as práticas discursivas integradas no discurso empresarial se reconfiguram no discurso da marca.

\section{PALAVRAS-CHAVE: LINGUAGEM •COMUNICAÇÃO・DISCURSO •DISCURSO EMPRESARIAL・DISCURSO DA MARCA.}

\section{Abstract}

People are involved in work processes, in economic and social structures in which the operationalization of a given discourse is reconfigured into new practices and their respective organizational structures. Language, in its dialectical relationship with society, is part of these changes. This testimony aims to map ongoing discursive changes through a personal view, discussing how the field of linguistics applied to business emerges and is adapted, as well as how discursive practices integrated into the managerial discourse are reconfigured into brand discourse.

\section{KEYWORDS: LANGUAGE・COMMUNICATION・DISCOURSE・ENTREPRENEURIAL DISCOURSE・BRAND DISCOURSE.}

\section{Resumen}

Las personas se involucran en procesos de trabajo, en estructuras económicas y sociales en las cuales la operacionalización de un discurso determinado se reconfigura en nuevas prácticas y respectivas estructuras organizativas. El lenguaje en su relación dialéctica con la sociedad es parte de este proceso de cambio. Este texto pretende mapear los cambios discursivos en curso a través de una mirada personal, siendo testigo de cómo surge y se adapta el campo de la lingüística aplicada a las empresas y de qué manera las prácticas discursivas integradas en el discurso empresarial se reconfiguran en un discurso de marca. 


\section{INTRODUÇÃO}

Hoje, reconhecemos o modo como as mudanças no uso da linguagem estão ligadas a processos sociais e culturais mais amplos. No período de tempo de uma vida humana, o indivíduo tem de se adaptar a diferentes tecnologias, a novos conhecimentos e valores e a novas formas de estar e de se relacionar com os outros, mediando o conhecimento, os valores, e essas relações pelo uso da linguagem. Neste enquadramento, o presente depoimento consubstancia-se num processo construído ao longo de uma vida académica e profissional, materializando um testemunho e um olhar pessoal de como as mudanças sociais, a expansão do conhecimento da área da linguística aplicada às empresas emerge e se adapta e as práticas discursivas integradas no discurso empresarial se reconfiguram como conhecimento emergente - o discurso da marca.

Peter Drucker, o fundador da gestão moderna, consciente das características desta sociedade, refere a necessidade de adequação do homem à variável de atualização do conhecimento como condição essencial para não se tornar obsoleto: "Na sociedade das organizações [...] é sensato assumir que alguém com qualquer conhecimento terá de adquirir conhecimento novo em cada quatro ou cinco anos ou tornar-se-á obsoleto" (Drucker, 1992, p.96)1. Esta constatação fora testemunhada anteriormente por Raymond Williams, cujo trabalho contribuiu de forma determinante para a autonomia dos estudos culturais em Inglaterra e que, após ter estado ausente da Universidade de Cambridge durante quatro anos e meio, aquando da guerra com a Alemanha e o Japão, sente, ao regressar à universidade, o incómodo da inadaptação referente a um mundo do qual estivera distanciado, verbalizando-a, em simultâneo com um companheiro de guerra, da seguinte forma: "o facto é que eles simplesmente não falam a mesma língua"(Williams, 1988, p.11)2.

Os testemunhos dos teóricos e fundadores das áreas da gestão e dos estudos culturais trazem à evidência, respetivamente, a importância do conhecimento e da linguagem como elementos cruciais na nossa sociedade e, acrescentaria, como força motriz emancipatória dos povos. Conhecimento e linguagem constituem os elementos norteadores para o propósito geral do presente depoimento: mapear mudanças discursivas inscritas em áreas científicas em contextos empresariais/organizacionais na última década do século XX e nas duas primeiras décadas do século XXI. Este início da segunda década do novo milénio parece ser o momento oportuno para olhar para trás e identificar mudanças em progresso operadas no tempo, considerando o momento de relativa estabilização do conhecimento novo (as marcas).

Dado a minha área científica de atuação ser a linguística aplicada, a abordagem adotada é transdisciplinar (Fairclough, 2003), na qual a investigação é um processo de confluência de diferentes disciplinas que dialogam no universo das empresas, como a linguística, a gestão e o direito e, simultaneamente, transdisciplinar no que refere a diferentes abordagens de natureza qualitativa relativas ao tema de investigação e ao quadro teórico no qual o estudo se inscreve.

Delineado o contexto e o respetivo enquadramento, o presente trabalho visa traçar um percurso da área científica da linguística aplicada às empresas, à luz da investigação que venho desenvolvendo desde 1991, mapeando trabalhos fundamentais para este processo, identificando a fluidez deáreas científicas afins na consolidação de conhecimento e na emergência de conhecimento novo.

Deste modo, após a introdução, na qual se contextualiza o objeto de estudo, se situa o quadro teórico e o objetivo do estudo, no primeiro ponto do artigo, intitulado "Da comunicação ao discurso: uma perspetiva dos anos 1990", são enunciados estudos que, na sua materialização em forma de textos, se configuram como conhecimento canónico inscrito numa área mais abrangente do estudo da linguagem, trazendo à evidência a confluência nos objetos de estudo de áreas afins.

1 No original: "In the society of organization [...] it is safe to assume that anyone with any knowledge will have to acquire new knowledge every four or five years or become obsolete". 2 No original: "the fact is, they just don't speak the same language". 
No segundo ponto, "Do discurso empresarial ao discurso da marca", é apresentado um conjunto de circunstâncias e de trabalhos que trouxeram a marca como um objeto de estudo de natureza semiótico-discursivo para a constelação dos estudos em linguística aplicada às marcas. Por fim, em forma de conclusão, recorremos a exemplos de diferentes paradigmas de trabalho, mostrando a nível lexical que a mudança social traz sempre a mudança de linguagem. Sendo esta um instrumento de poder, o conhecimento novo em articulação com o entendimento de linguagem como um sistema semiótico reforçam 0 empoderamento dos indivíduos nas suas estratégias emancipatórias.

\section{DA COMUNICAÇÃO AO DISCURSO: UMA PERSPETIVA DOS ANOS 1990}

Numa apreciação geral da investigação desenvolvida nos anos 1990, inscrita fundamentalmente no contexto europeu, esta década apresenta um crescente interesse, manifestado ao nível internacional, de áreas inscritas em Ciências da Linguagem e afins pelo estudo da linguagem aplicado às organizações.

Em conformidade, Taylor e Cooren (1997) referem o trabalho exaustivo levado a cabo por Barry Smith, em que 0 autor faz a revisão da literatura desenvolvida sobre as organizações e encontra o enfoque dos trabalhos na comunicação na organização. Adianta que mais recentemente [sic] a comunicação seja encarada como organização, tomando esta vertente uma maior expressão. A mudança de perspetiva mostra que, quando os académicos da comunicação organizacional estudam a organização, eles estão interessados no funcionamento da comunicação como expressão e como criação da estrutura organizacional.

A perspetiva da comunicação como organização vai tomando cada vez maior expressão, dando corpo a um campo de investigação que é simultaneamente partilhado pelo discurso.

A propósito desta área comum de investigação, Bargiela-Chiapini e Nickerson (2002) posicionam-se claramente a favor da designação de discurso, por esta ser a que melhor se enquadra na consolidação disciplinar que advogam, conforme revelam as suas próprias palavras:

A escolha da denominação disciplinar 'business discourse' em vez de 'business communication' é significativa e deliberadamente programática. Sugere que a consolidação disciplinar progressiva só pode ser alcançada através de um compromisso com 0 envolvimento epistemológico e metodológico entre disciplinas baseadas no discurso, o que será o primeiro passo para definir um propósito comum em torno da qual a investigação colaborativa possa florescer. (Bargiela-Chiappini; Nickerson, 2002, p.273, tradução nossa) $)^{3}$

O estudo do discurso permite-nos, de uma forma geral, relacionar a conversa do dia a dia da organização com questões mais amplas da estrutura organizacional. Esta ideia é verbalizada por Boden (1994):

É por meio de telefonemas, reuniões, sessões de planeamento, conversas de vendas e conversas de corredor que as pessoas informam, se divertem, atualizam, fofocam, revisam, reavaliam, raciocinam, instruem, argumentam, debatem, contestam e efetivamente constituem os momentos, mitos e, ao longo do tempo, a própria estruturação da organização. (p.8, grifo do autor) ${ }^{4}$

\footnotetext{
3 No original: "The choice of the disciplinary label of 'business discourse' rather than 'business communication' is significant and deliberately programmatic. It suggests that progressive disciplinary consolidation can only be achieved through a commitment to epistemological and methodological sharing between discourse-based disciplines which will be the first step towards defining a common purpose around which collaborative research can flourish".

4 No original: "It is through the telephone calls, meetings, planning sessions, sales talks, and corridor conversations that people inform, amuse, update, gossip, review, reassess, reason, instruct, revise, argue, debate, contest, and actually constitute the moments, myths and, through time, the very structuring of the organization".
} 
Em cada uma das práticas sociais enunciadas, as práticas comunicativas nas quais os seus membros se envolvem contribuem para o processo em curso na organização e, por conseguinte, para a constituição da própria realidade social.

As áreas científicas do conhecimento, tal como as línguas ou outros organismos vivos, estão sujeitas à variação ou mudança que caracteriza todas as formas de vida. Nesse sentido, podemos assumir que estes organismos nascem, crescem, decaem e morrem ou se transformam. As metáforas usadas para a vida servem aqui para referir a instabilidade observada no que refere à delimitação das áreas do conhecimento na sua aplicação ao estudo das organizações. Com efeito, a abordagem ao estudo da comunicação na organização é exemplo desse progressivo declínio. Esta constatação é igualmente observada para a denominação do objeto de estudo.

\section{A instabilidade da área e as denominações}

Uma revisão da literatura relativa às denominações do objeto de estudo nos anos 1990 permite constatar que este recebeu diferentes classificações. Termos como business discourse (discurso de negócios) (Bargiela-Chiappini5; Nickerson, 1999, 2002; Ehlich; Wagner, 1995); discurso da gestão (managerial discourse) (Silvestre, 1996, 1998); professional discourse (discurso profissional) (Gunnarsson et al., 1997); institutional discourse (discurso institucional) (Agar, 1985; Drew; Sorjonen, 1997); professional communication (comunicação profissional) (Pan; Scollon, 2002); organizational communication (comunicação organizacional) (Taylor; Cooren, 1997); e organizational discourse (discurso organizacional) (ledema, 2003; Mumby; Clair, 1997) coexistem para designar objetos de estudo similares em áreas afins.

Alguns pontos parecem intersetar as diferentes classificações usadas - todas exploram a linguagem em uso, quer escrita quer oral, como um processo socialmente situado em contextos profissionais -, sejam estas organizações, instituições ou empresas. As perspetivas que são tomadas nos diferentes trabalhos para sustentarem as diferentes classificações podem, porém, ser eventualmente diferentes.

Gunnarsson et al. (1997), por exemplo, usam o termo discurso profissional como uma hiper-categoria na qual incluem domínios profissionais como o legal, o médico, o trabalho social e o discurso educacional, bem como o discurso científico em contextos organizacionais ou empresariais. 0 enfoque subjacente à classificação é fundamentalmente a diversidade dos domínios profissionais e não tanto a natureza do contexto, i.e., se se trata de uma organização ou de objetos sociais específicos, como são a instituição ou a empresa.

Os autores referem a natureza arqueológica da construção do discurso profissional, alegando que este pode ser localizado e estudado tanto numa perspetiva de longo como de curto prazo. A continuidade das práticas profissionais estende-se ao longo dos anos. Ao mesmo tempo, estas são manifestadas apenas sob circunstâncias históricas concretas (Gunnarsson et al., 1997).

Silvestre (1996) segue esta perspetiva arqueológica quando focaliza o seu trabalho no discurso da gestão, explorando como a disciplina estabelece o seu próprio cânone histórico na sua formação e emergência como unidade discursiva. Na exploração da gestão como processo, analisa a forma como o poder é exercido através de regulamentos ilustrativos de dois modelos de gestão, um datado de 1890 de uma fábrica americana e outro de uma empresa também americana, datado de 1994. As classificações "discurso profissional", "discurso institucional", "discurso empresarial" ou "business discourse" também podem ser aplicadas no seu trabalho. Contudo, o carácter profissional foi o elemento determinante para a classificação. A escolha resultou do enfoque no grupo socioprofissional (gestores), no seguimento da noção de Scollon de communities of practice,

5 Francesca Bargiela-Chiappini, da Universidade de Nottingham-Trent, é um nome incontornável em business discourse. No entanto, adotou anteriormente a designação corporate discourse (Bargiela-Chiappini; Harris, 1997). 
nas quais interessa analisar como este grupo exerce o poder: os processos, objetivos, modos de trabalhar, interação mediada partilhada pelo grupo, inscrito em empresas.

Esta perspetiva também é usada por Bargiela-Chiappini e Nickerson (1999), quando referem que o status dos interactantes pode ser visto como um elemento decisivo na distinção entre discurso profissional e business discourse. As autoras optaram pela última classificação, sustentado pelo facto de o campo de atividade ser o negócio (business ${ }^{6}$ ), definindo-o como : "[...] falar e escrever entre indivíduos cujas principais atividades de trabalho e interesses estão no domínio de fazer negócios" (Bargiela-Chiappini; Nickerson, 1999, p.2).

Na continuação do trabalho desenvolvido nos anos 1990, no âmbito do discurso da gestão, Silvestre (2003, 2004) expande 0 enfoque da investigação, optando pela denominação 'discurso empresarial's. Cabe aqui fazer um parêntesis para passar à explicação da escolha.

Mumby e Clair (1997, p.181) definem organização como "um coletivo social, produzido, reproduzido e transformado por meio de práticas comunicativas contínuas, interdependentes e orientadas a objetivos dos seus membros" (tradução nossa). Esta definição parece, de alguma forma, restringir outras definições do termo, nomeadamente a apresentada pelo Dicionário de Sociologia, referindo que "organização" designa simultaneamente um objeto social e um problema central da sociologia da ação. Relativamente à primeira aceção, refere-se o caráter estrutural que lhe subjaz:

O objecto social é bem conhecido: as administrações públicas, as empresas industriais, comerciais e de serviços, tal como os partidos políticos e as associações de toda a espécie de que somos ao mesmo tempo os assalariados; os membros e/ou militantes e os clientes, são todas elas organizações, isto é, conjuntos humanos ordenados e hierarquizados em ordem a assegurar a cooperação e a coordenação dos seus membros para determinadas finalidades [.... (Boudon et al., 1990, p.181)

Embora integrando as empresas, o termo organizacional revela-se demasiado abrangente, sendo a escolha da designação 'discurso empresarial' mais adequada à dimensão restrita do objeto de estudo, muito mais próxima do significado proposto pelo Dicionário de Língua Portuguesa Contemporânea da Academia da Ciências de Lisboa (2001) na quarta alínea da entrada "empresa": "4. Econ. Organização particular ou estatal que produz bens ou serviços, com vista à obtenção de lucros; companhia, firma". Esta definição remete a um contexto de exploração industrial ou comercial, ou seja, a uma sociedade ou companhia que explora qualquer ramo de indústria, comércio ou serviços. Orientada para a especificação da missão, para o objeto ou finalidade que constitui a razão de ser da empresa, esta definição corresponde ao tipo de organização que constitui o meu objeto de estudo.

\section{O quadro teórico e metodológico: no trilho de uma abordagem}

No início do trabalho de investigação e perante a inexistência de internet, à data, para a procura e recolha bibliográfica, visitas temporárias à universidade de Lancaster, Reino Unido, em curtas estadias durante as férias de verão, foram realizadas em dois anos consecutivos a fim de contactar Norman Fairclough para aprofundar o conhecimento sobre o quadro teórico e

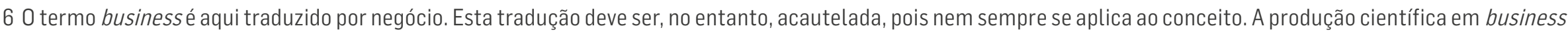
discourse/business communication evidencia que o termo é usado diferenciadamente.

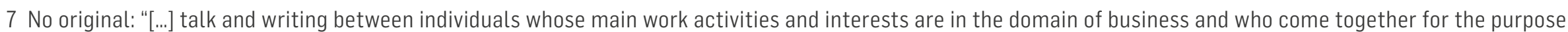
of doing business".

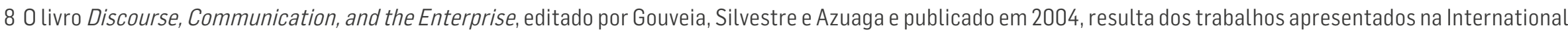

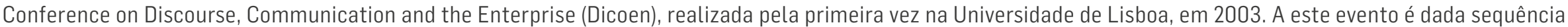

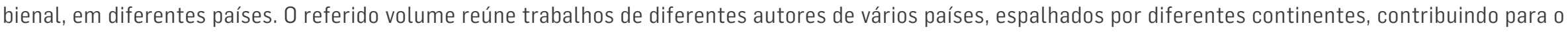
mapeamento de abordagens aos objetos de estudo e respetivos enquadramentos teóricos e metodológicos realizados na época.

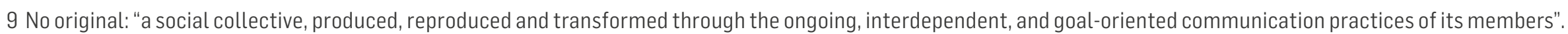


simultaneamente procurar bibliografia para esta área de aplicação inexistente em Portugal. À época, Fairclough tinha publicado apenas os livros Language and Power (1989) e Discourse and social change (1992). 0 primeiro propósito foi alcançado com a generosidade da disponibilização de todo o seu material na forma de working papersque viriam mais tarde a ser publicados na forma de artigos e de livros, bem como autorização para frequentar a biblioteca da universidade na condição de visitante. A grandiosidade das bibliotecas universitárias inglesas não era comparável às portuguesas. 0 acesso à revista Language \& Societyrevelou-se muito frutífero dada a importância da revista para a consolidação da análise crítica do discurso. 0 segundo propósito revelou-se árduo diante da inexistência da área de aplicação, tendo sido defrontada com a necessidade de definir e identificar abordagens e metodologias que pudessem ajudar a compreensão do fenómeno em estudo. Assim, para o trabalho desenvolvido contribuíram várias áreas e disciplinas, nomeadamente a linguística, a sociolinguística, a pragmática, a análise conversacional, a análise do discurso, a comunicação e a gestão.

Interessava, na época, procurar e sistematizar, nos diferentes estudos na área e áreas afins, as diferentes abordagens de forma a melhor identificar o percurso a seguir (para um maior desenvolvimento, ver Bargiella-Chiappini; Nickerson; Planken, 2007; Mumby; Clair, 1997). Da revisão da literatura, tinha ficado com interesse pelo entendimento da comunicação como organização. Do discurso organizacional interessava a perspetiva dos autores que estudavam não apenas o discurso nas organizações, mas este como constitutivo das organizações. Em conformidade com as minhas preocupações sociais, foi ficando claro que a via seria uma abordagem preocupada com as relações entre discurso, poder e ideologia. A perspetiva crítica poderia fornecer algum entendimento sobre relações de poder e possibilidades emancipatórias alternativas.

Chegados aqui e considerando o propósito deste trabalho e a relevância do uso do termo discurso, de modo específico - 0 discurso empresarial, o discurso da marca, o discurso neoliberal, por exemplo -, cabe citar uma definição para uma maior clarificação do termo. Chouliaraki e Fairclough (1999) apresentam-no da seguinte forma:

Usaremos o termo 'discurso' para referir os elementos semióticos das práticas sociais. 0 discurso inclui, portanto, a linguagem (escrita ou falada e em combinação com outros [recursos] semióticos como, por exemplo, música no canto), comunicação nãoverbal (expressões faciais, movimentos corporais, gestos etc.) e visuais (por exemplo, fotografias, filme). 0 conceito de discurso pode ser compreendido como uma perspetiva particular destas variadas formas de semioses - vê-as como momentos de práticas sociais na sua articulação com outros momentos não discursivos. (p.38, tradução nossa)

\section{DO DISCURSO EMPRESARIAL AO DISCURSO DA MARCA}

A globalização económica trouxe grandes mudanças para as empresas, instituições e sociedade, em geral, e a linguagem faz parte dessas mudanças. As pessoas estão envolvidas em processos de trabalho, em estruturas económicas e sociais nas quais a operacionalização de um determinado discurso se vai reconfigurando em novas práticas e estruturas organizacionais. Este contexto global a par com uma sociedade que sente a competitividade internacional levou o governo português a estabelecer como prioridade o desenvolvimento das marcas como forma de ultrapassar a crise sentida há alguns anos em Portugal, nomeadamente nos setores dos têxteis e calçados, que, à época, não tinham marca própria.

No contexto da globalização, o termo marca (brand) vem se distanciando do significado do século XIX, quando era usado para designar as empresas fabricantes. Na década de 1990, o termo manifesta uma expansão semântica e maior ocorrência de uso. Hoje, o termo, amplamente generalizado, é usado para referir produtos, bens, serviços, empresas, instituições, pessoas, territórios, países.

Neste contexto socioeconómico, no qual se procura uma maior proximidade entre a academia e o tecido empresarial, associado à crescente necessidade da internacionalização das universidades, a parceria académica existente entre as instituições 
Univates, em Lajeado-RS, Brasil, e IPLeiria, Portugal, revelou-se profícua. Na condição de pesquisadora convidada, Silvestre integra, em 2007, um projeto sobre criação da marca na cadeia produtiva de leite no Rio Grande do Sul para dar resposta a necessidades de mercado. Nesse projeto multidisciplinar, a minha participação como pesquisadora decorre do background em análise crítica do discurso e em semiótica social.

Da década de 1990 chegaram até nós nomes de referência internacional, como Aaker $(1991,1996)$, seguidos por outros como Keller (1998), Kapferer (1991, 1992), e artigos da Harvard Business Reviewe do Journal of Brand Management sobre o estudo da marca, realizados fundamentalmente na perspetiva do marketing.

No âmbito do projeto, e numa procura conjunta (com Elizete Kreutz) levada a cabo na internet sobre marca/brand, obtivemos um número limitado de títulos. Em Portugal, identificámos a existência de um livro com trabalho conjunto com o Brasil (Lencastre, 2007) ${ }^{10}$. Para a pesquisa efetuada sobre discurso da marca, não foi identificada qualquer entrada. Esse momento marca o início do percurso em discurso (multimodal) da marca, em Portugal e no Brasil. 0 trabalho conjunto de Elizete Kreutz (RS-Brasil), Carminda Silvestre (Portugal), Francisco Mas (Chile), Fernando Olivares (Espanha), entre outros colegas provenientes inicialmente destes países, desenvolve-se em várias frentes, como a criação de curso de pós-graduação em Comunicação Estratégica \& Branding, lecionado em 2009, na sua primeira edição, na Feevale, Novo Hamburgo, Brasil, e na Universidade Mayor de Santiago do Chile. Este curso de pós-graduação é indexado e registado com o Observatório de Marcas. Em 2013, é criado o curso de Branding \& Business, lecionado na Univates, que completou a sua quinta edição em 2020. Em Portugal, o curso foi oferecido pelo Politécnico de Leiria, mas a crise económica durante a Troika, em Portugal, inviabilizou 0 curso pelo reduzido número de candidatos. Associado ao Observatório de Marcas, é publicada a BrandTrends Journal, revista científica da área da comunicação estratégica e branding, e são organizadas conferências internacionais, com início em Leiria, Portugal, em 2014, e seguidas em universidades no Brasil. Os contributos de todos os artefactos enunciados cooperam no aprofundamento e expansão do estudo da marca e, especificamente, na perspetiva da sua abordagem semiótico-discursiva.

Na primeira década do século XXI, as publicações no âmbito do estudo da marca aumentam nas áreas do marketing, gestão, comunicação, direito, publicidade, design, embora marcadamente determinadas pela respetiva área científica. A inexistência de literatura que permitisse estudar a marca numa abordagem semiótico-discursiva levou-me a dar início ao estudo da marca. Neste contexto, a abordagem desenvolvida no âmbito deste tema de investigação tem por base o discurso empresarial iniciado em 1991, em Portugal (Silvestre, 1996, 1998, 2003, 2004), inscrito no quadro teórico da análise crítica do discurso" (Fairclough, 1989, 1995), e posteriormente da semiótica social'12 (Kress; Hodge, 1988; Kress; van Leeuwen, 1996; van Leeuwen, 2005) e da linguística sistémico-funcional, iniciada nos anos 1960 por M. A. K. Halliday, cuja perspetiva de linguagem é a de

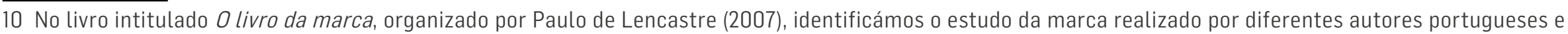

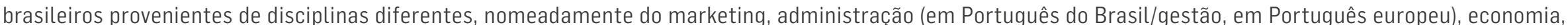

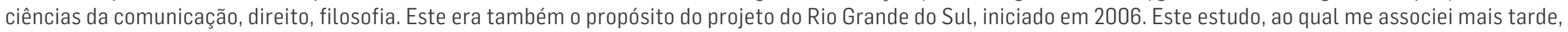

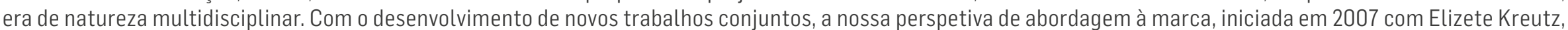
toma a forma transdisciplinar.

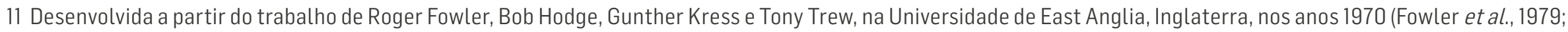

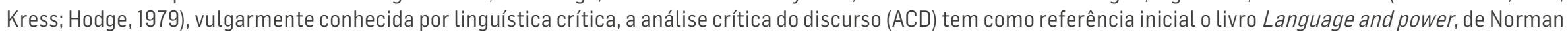

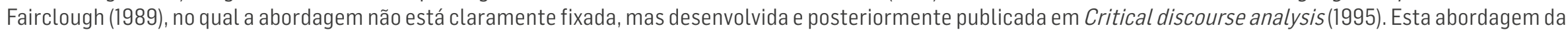

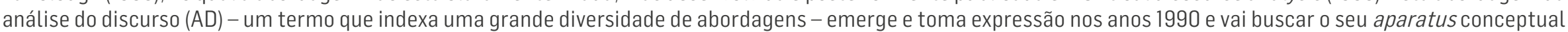

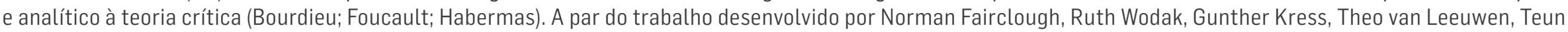

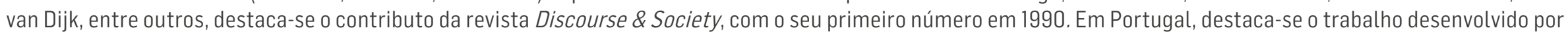

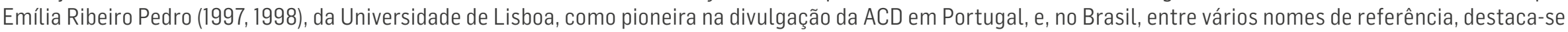
o contributo de Izabel Magalhães, da UnB, com as traduções para língua portuguesa da obra de Norman Fairclough.

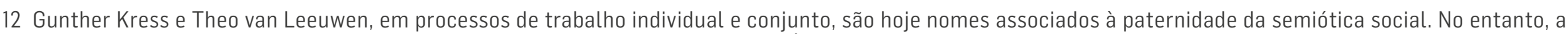

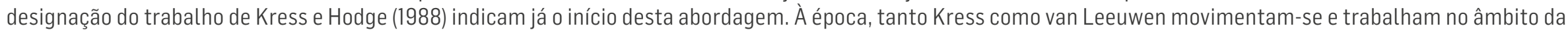

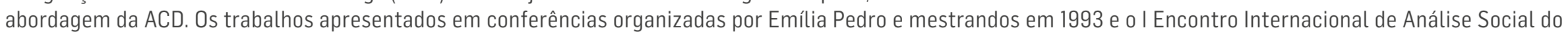

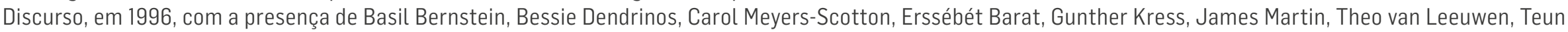
van Dijk - hoje conhecido pelo Encontro da Arrábida - dão testemunho disso.
} 
um sistema semiótico (Halliday, 1994), e na qual a ACD e a semiótica social vão buscar os ensinamentos fundamentais. É apropriado referir que desse quadro teórico e da partilha e discussões com colegas envolvidos no projeto conjunto resultou 0 primeiro trabalho publicado, que dá início a este empreendimento do estudo da marca numa perspetiva semiótico-discursiva (Silvestre et al., 2009). Esta perspetiva vem sendo disseminada e está corporizada no material distribuído aos alunos de pósgraduação das instituições e países acima enunciados entre 2009 e 2020 (Silvestre, 2010); em publicações conjuntas com alunos (Pinto; Silvestre, 2012); em artigos dispersos em journals (Silvestre; Marques, 2012); em atas de conferências (Kreutz, 2011; Silvestre; Marques, 2017); em partes de livros (Silvestre; Marques, 2021), para referir apenas alguns exemplos.

Para além da criação e disseminação do conhecimento, a aplicação deste novo conhecimento, por meio de pareceres técnicos, tem revertido a favor das empresas em contextos de disputas legais. Refira-se, a título exemplificativo, o caso da marca Switzer, empresa portuguesa a quem foi instaurado um processo judicial por uma agência Suíça. Também o caso da Cadbury Adams Brasil Indústria e Comércio de Produtos Alimentícios Ltda, sediada em São Paulo, titular da marca Chiclets, que instaura um processo judicial contra a sociedade brasileira Docile Alimentos Ltda., empresa do Rio Grande do Sul, titular da marca XClé (Kreutz; Silvestre, 2019). Nos casos em que foram apresentados os pareceres técnicos sobre a marca aos respetivos advogados de defesa, com base neste conhecimento novo adquirido, as empresas menores ganharam os processos judiciais instaurados por grandes empresas e multinacionais.

\section{CONSIDERAÇÕES FINAIS}

A sociedade tem sofrido grandes mudanças no campo do trabalho, verificando-se a emergência de novos paradigmas na estrutura do trabalho, nomeadamente do paradigma fordista ao neoliberal. A linguagem é parte integrante dessas mudanças. A própria organização, ao nível lexical, tem sido nomeada fábrica (milll factory), no século XIX; empresa (company), no século XX; e, na última década do século XXI, constatamos um crescente uso do termo marca (brand) a par com o uso de empresa como forma de se referirem a elas próprias. Cada um destes itens lexicais carrega uma carga ideológica específica no mundo do trabalho. Também uma nova classificação foi criada nos últimos anos na esfera do processo produtivo - o gestor de marca (brand manager). Hoje, encontramos gestores de marca tanto em empresas como em instituições públicas, como é o caso da Câmara Municipal de Torres Vedras, que criou este posto em 2016. As mudanças ocorridas não se restringem, assim, ao nível lexical. Estas ocorrem numa relação dialética com as estruturas organizacionais e sociais.

A linguagem é um instrumento de poder. Neste mundo globalizado, com ferramentas tecnológicas cada vez mais sofisticadas, com o incremento do sistema semiótico visual em detrimento do sistema verbal na publicidade dos bens, produtos ou serviços, necessitamos adquirir conhecimento novo e de aprofundar o conhecimento da linguagem, na sua aceção de sistema semiótico, e dos seus mecanismos na articulação e produção de significados, a fim de se alcançar um maior empoderamento, no qual os mais poderosos possam ser contestados e as assimetrias, sejam elas de que natureza forem, se esbatam. No estudo das marcas, a sobreposição de uma disciplina em relação a outra promove a perspetiva única, empobrecendo o objeto de estudo. 0 diálogo entre as diferentes disciplinas numa abordagem transdisciplinar é fator de enriquecimento e possibilita, por conseguinte, analisar as diferentes faces do problema - a marca.

\section{REFERÊNCIAS}

AAKER, David A. Managing brand equity. New York: John Wiley \& Sons, 1991.

AAKER, David A. Building strong brands. New York: John Wiley \& Sons, 1996. 


\section{ANO 18 • NÚMERO 36 • MAIO / AGOSTO • ORGANICOM}

\section{DO DISCURSO EMPRESARIAL AO DISCURSO DA MARCA - UM OLHAR}

AGAR, Michael. Institutional discourse. Text, Berlin, v.5, n.3, p.147-168, 1985.

BARGIELA-CHIAPPINI, Francesca; HARRIS, Sandra J. Managing language: the discourse of corporate meetings. Amsterdam: John Benjamins, 1997.

BARGIELA-CHIAPPINI, Francesca; NICKERSON, Catherine. Business writing as social action. In: BARGIELA-CHIAPPINI, Francesca; NICKERSON, Catherine (ed.). Writing business. genres, media and discourses. London: Longman, 1999. p.1-32.

BARGIELA-CHIAPPINI, Francesca; NICKERSON, Catherine. Business discourse: old debates, new horizons. IRAL, Berlin, v.40, n. 4, p.273-286, 2002.

BARGIELA-CHIAPPINI, Francesca; NICKERSON, Catherine; PLANKEN, Brigitte. Business discourse. New York: Palgrave Macmillan, 2007.

BODEN, Deidre. The business of talk. Organizations in Action. London: Polity Press, 1994.

BOUDON, Raymond; BESNARD, Philippe; CHERKAOUI, Mohamed; LÉCUYER, Bernard-Pierre (org.). Dicionário de Sociologia. Lisboa: Dom Quixote, 1990.

CHOULIARAKI, Lilie; FAIRCLOUGH, Norman. Discourse in late modernity. Rethinking critical discourse analysis. Edinburgh: Edinburgh University Press, 1999.

DREW, Paul; SORJONEN, Marja-Leena. Institutional dialogue. In: VAN DIJK, Teun (ed.). Discourse studies: a multidisciplinary introduction, volume 2. Discourse as social interaction. London: Sage, 1997. p.92-118.

DRUCKER, Peter. The new society of organizations. Harvard Business Review, Cambridge, MA, 1992. Disponível em: https:// hbr.org/1992/09/the-new-society-of-organizations. Acesso em: 14 set. 2021.

EHLICH, Konrad; WAGNER, Johannes (ed.). The discourse at business negotiation. Berlin: De Gruyter, 1995.

FAIRCLOUGH, Norman. Language and power. London: Longman, 1989.

FAIRCLOUGH, Norman. Critical discourse analysis. The critical study of language. London: Longman, 1995.

FAIRCHOUGH, Norman. Analysing discourse: text analysis for social research. London: Routledge, 2003.

FOWLER, Roger; HODGE, Bob; KRESS, Gunther; TREW, Tony. Language and control. London: Routledge, 1979.

GUNNARSSON, Britt-Louise; LINELL, Per; NORDBERG, Bengt (ed.). The construction of professional discourse. London: Routledge, 1997.

HALLIDAY, Michael Alexander Kirkwood. An introduction to functional grammar. 2.ed. London: Edward Arnold, 1994.

KRESS, Gunther; HODGE, Robert. Language as ideology. London: Routledge, 1979. 


\section{ANO 18 • NÚMERO 36 • MAIO / AGOSTO • ORGANICOM}

\section{DO DISCURSO EMPRESARIAL AO DISCURSO DA MARCA - UM OLHAR}

IEDEMA, Rick. The medical record as organizing discourse. Document Design, Amsterdam, v.4, n.1, p.64-84, 2003.

KAPFERER, Jean-Noël. Marcas: capital de empresa. Lisboa: Cetop, 1991.

KAPFERER, Jean-Noël. Strategic brand management. new approaches to creating and evaluating brand equity. New York: The Free Press, 1992.

KELLER, Kevin Lane. Strategic brand management-building, measuring and managing brand equity. New Jersey: Prentice Hall, 1998.

KRESS, Gunther; VAN LEEUWEN, Theo. Reading images: the grammar of visual design. London: Routledge, 1996.

KRESS, Gunther; HODGE, Robert. Social semiotics. Cambridge: Polity Press, 1988.

KREUTZ, Elizete de Azevedo; SILVESTRE, Carminda. Chiclets versus Xclé: uma análise multimodal das marcas no processo de disputa legal. Language and Law/ Linguagem e Direito, Porto, v.6, n.1, p.43-62, 2019.

KREUTZ, Elizete de Azevedo. 0 discurso multimodal das marcas mutantes. In: CONGRESSO BRASILEIRO DE CIÊNCIAS DA COMUNICAÇÃO, 34., 2011, Recife. Anais [...]. Recife: Intercom, 2011.

LENCASTRE, Paulo (org.). O livro da marca. Lisboa: Dom Quixote, 2007.

MUMBY, Dennis K.; CLAIR, Robin. Organizational discourse. In: VAN DIJK, Teun (ed.). Discourse studies: a multidisciplinary introduction, volume 2. Discourse as social interaction. London: Sage, 1997. London: Sage, 1997. p.181-205.

PAN, Yuling; SCOLLON, Suzanne Wong; SCOLLON, Ron. Professional communication in international settings. Oxford: Blackwell Publishers, 2002.

PEDRO, Emilia Ribeiro (ed.). Discourse analysis: proceedings of the 1st international conference on discourse analysis. Lisboa: Colibri, 1997.

PEDRO, Emilia Ribeiro (org.). Análise crítica do discurso: uma perspectiva sócio-política e funcional. Lisboa: Caminho, 1998.

PINTO, Manuel; SILVESTRE, Carminda. Un discurso para la cohesión social. El processo semiótico-discursivo en la (re) construcción de marca chile en el bicentenário, Revista Chilena de Diseño, Santiago, n²2, p.41-55, 2012.

SILVESTRE, Carminda; MARQUES, Gorete. Porto - um estudo de caso na perspetiva do discurso multimodal da marca. In: CONGRESSO INTERNACIONAL DE MARCAS/BRANDING- ECONOMIA CRIATIVA, 3., 2017, São Paulo. Anais [...]. São Paulo: Belas Artes, 2017. p.278-294. Disponível em: https://www.belasartes.br/brandingcongress/downloads/anais-v3.pdf. Acesso em: 14 set. 2021.

SILVESTRE, Carminda; MARQUES, Gorete. A metáfora contextual visual como recurso semiótico da marca na projeção de valores. In: SILVA, Clayton Robson Moreira da (org.). Estudos organizacionais: sociedade e marketing e cadeias produtivas. Paraná: Atena, 2021. p.16-28. 


\section{ANO 18 • NÚMERO 36 • MAIO / AGOSTO • ORGANICOM}

DO DISCURSO EMPRESARIAL AO DISCURSO DA MARCA - UM OLHAR

SILVESTRE, Carminda. Modalidades do poder no discurso da gestão - uma perspectiva de análise crítica do discurso. 1996. Dissertação (Mestrado em Linguística Inglesa)-Faculdade de Letras, Universidade de Lisboa, Lisboa, 1996.

SILVESTRE, Carminda. The construction of the subject - a diachronic perspective. In: LUNDQUIST, Lita; PICHT, Heribert; QVISTGAARD, Jacques (ed.). LSP identity and interface research, knowledge and society. Denmark: Copenhagen Business School, 1998. p.505-513.

SILVESTRE, Carminda. Permanências e mudanças nas relações de género no discurso empresarial: das representações às práticas de chefia - um estudo de análise crítica do discurso. 2003. Tese (Doutorado) - Faculdade de Letras, Universidade de Lisboa, Lisboa, 2003.

SILVESTRE, Carminda. Top positions in Portuguese entrepreneurial context: a place of male and female asymmetries. $/ \mathrm{n}$ : GOUVEIA, Carlos; SILVESTRE; Carminda; AZUAGA, Luísa (ed.). Discourse, communication and the enterprise. Lisboa: Ulices, 2004. p.283-304.

SILVESTRE, Carminda. O discurso multimodal da marca. 2.ed. Rio Grande do Sul: Feevale, 2010.

SILVESTRE, Carminda; KREUTZ, Elizete de Azevedo; MAS, Fancisco; VIEIRA, Josenia Antunes; MÜLLER, Thaís Carnieletto. 0 discurso da marca: o caso Natura e Natura Pura. In: CONGRESSO LUSOCOM, 8., 2009, Lisboa. Anais [...]. Lisboa: Universidade Lusófona, 2009. p.344-359.

SILVESTRE, Carminda; MARQUES, Gorete. Discurso multimodal da marca: contributos para o estudo da representação. BrandTrends Journal, Lajeado, v.2, n. 2, p.66-78, 2012.

TAYLOR, James; COOREN, François. What makes a communication 'organizational'? Journal of Pragmatics, Amsterdam, v.27, n.4, p.409-438, 1997.

VAN LEEUWEN, Theo. Introducing social semiotics. London: Routledge, 2005.

WILLIAMS, Raymond. Keywords - a vocabulary of culture and society. London: Fontana Press, 1988.

Artigo recebido em 16.05.2021 e aprovado em 08.09.2021. 